This item was submitted to Loughborough's Research Repository by the author.

Items in Figshare are protected by copyright, with all rights reserved, unless otherwise indicated.

\title{
Risk-adjusted measures of value creation in financial institutions
}

PLEASE CITE THE PUBLISHED VERSION

http://dx.doi.org/10.1111/j.1468-036X.2010.00540.x

\section{PUBLISHER}

(C) Blackwell Publishing Ltd

VERSION

AM (Accepted Manuscript)

\section{LICENCE}

CC BY-NC-ND 4.0

\section{REPOSITORY RECORD}

Milne, Alistair, and Mario Onorato. 2019. "Risk-adjusted Measures of Value Creation in Financial Institutions". figshare. https://hdl.handle.net/2134/15155. 
This item was submitted to Loughborough's Institutional Repository (https://dspace.lboro.ac.uk/) by the author and is made available under the following Creative Commons Licence conditions.

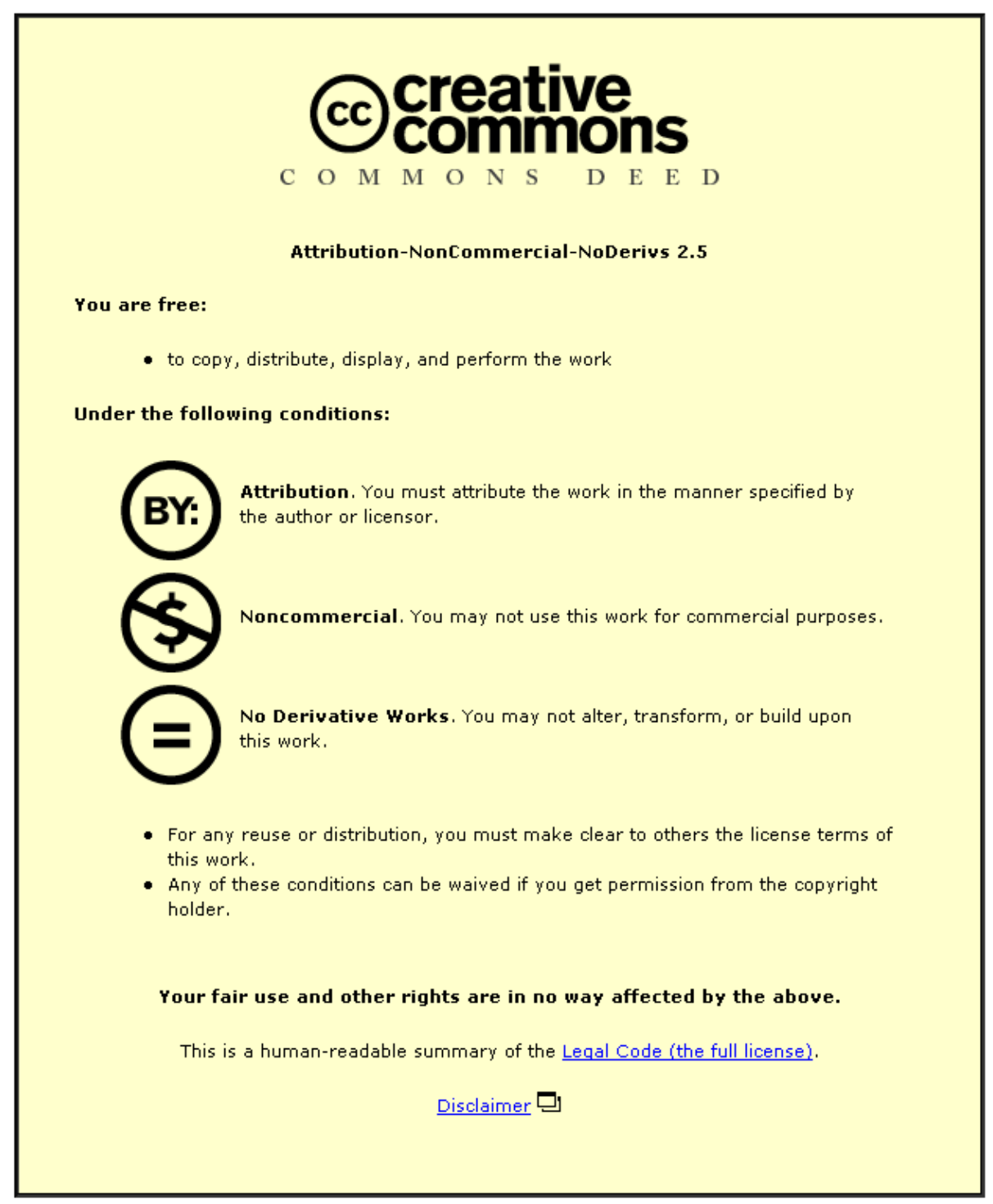

For the full text of this licence, please go to: http://creativecommons.org/licenses/by-nc-nd/2.5/ 


\title{
Risk-adjusted measures of value creation in financial institutions ${ }^{*}$
}

\author{
Alistair Milne $^{\dagger}$ and Mario Onorato
}

December, 2008

\begin{abstract}
Measuring value creation by comparing the RAROC of an exposure (the return on risk capital) with a single institution wide hurdle rate is inconsistent with the standard theory of financial valuation. We use asset pricing theory to determine the appropriate hurdle rate for such a RAROC performance measure. We find that this hurdle rate varies with the skewness of asset returns. Thus the RAROC hurdle rate should differ substantially between equity which has a right skew and debt which has a pronounced left skew and also between different qualities of debt exposure. We discuss implications for financial institution risk management and supervision.
\end{abstract}

Journal of Economic Literature number: G22, G31

Keywords: Asset Pricing, Banking, Capital Allocation, Capital Budgeting, Capital Management, Corporate Finance, Downside Risk, Economic Capital, Performance Measurement, RAROC, Risk Management, Value Creation, Hurdle Rate, Value at Risk

\section{Introduction}

Most of the world's large and internationally active financial institutions now use their risk-management systems for assessing risk-return tradeoffs. This practice is variously described as 'economic capital

\footnotetext{
${ }^{*}$ The views expressed here are not necessarily those of either the Bank of Finland or of Algorithmics. We are grateful for comments from Esa Jokivuolle, Mareen Benk and audiences at Cass Business School, the University of Lugano, Bocconi Univerity, the 2007 Chicago Enterprise Risk Management Workshop, the 2008 Campus for Finance conference, the 2008 European Financial Management Association and from three anonymous referees. Any remaining errors are our own responsibility.

${ }^{\dagger}$ Faculty of Finance, Cass Business School, City University, London; and Monetary Policy and Research Department, Bank of Finland, Helsinki email: amilne@city.ac.uk.

* Director, Algorithmics Inc \& Faculty of Finance, Cass Business School, City University, London. e-mail: monorato@algorithmics.com
} 
management' or 'capital allocation'. ${ }^{1}$ The most widely used capital allocation based value measure is RAROC, the ratio of expected revenues on a particular exposure to its contribution to institution wide risk capital $^{2}$. The numerator is expected returns over some time horizon (usually one year) net of all operational and funding costs. The denominator - risk capital - is an exposure specific measure of tail risk quantified using a combination of models, including VaR for market risk, Credit-VaR models for credit risk and other models for operational risk.

RAROC is nowadays also very actively promoted both by the consultancy industry and by regulator, and for a very wide range of applications, in commercial and investment banking, asset management and insurance. In order for financial institutions to be able to use their own internal models as part of the more advanced calculations of regulatory capital in pillar 1 of the Basel II accord, these models must pass a 'use test' i.e. they must be actively used by the bank for managing its own portfolio, not just constructed specially for regulatory compliance. The new Solvency II regulations for European insurance companies, which introduce similar approaches to capital regulation as Basel II for banks, provide similar encouragement for capital allocation. As a number of consultancy studies document it has become the most widely applied tool of financial valuation around the world, used by financial services firms for supporting decisions on portfolio allocations, business mix, product pricing, and employee remuneration. ${ }^{3}$

Measuring value creation by comparing RAROC of an exposure with a single institution wide RAROC hurdle rate which is the standard application of these techniques in the industry, is inconsistent with the standard theory of financial valuation, a point first identified by Crouhy et. al. (1999) and more fully developed by Milne and Onorato (2009). This theory, beginning with the contributions of Markovitz and of Arrow, teaches us that if investors are rational, risk-averse, and can exchange exposures freely with each other without significant trading costs, then they will all agree on a dollar present value for any tradeable financial asset (if not then there are unexploited gains from trade). Moreover this dollar present value should

\footnotetext{
${ }^{1}$ The major consultancy companies are a good source of information on how financial institutions apply these methods, see for example KPMG (2004) and PWC-EIU (2005) on their use in business management and Ernst and Young (2005) on their role in investor disclosure. For a recent published collection of practitioner writing see Dav (ed) (2006).

${ }^{2}$ Matten (2000, pp 146-166) describes RAROC alongside several related performance measures. The various acronyms (RAROC, RORAC, RARORAC, etc.) are not applied by practitioners in a consistent manner. While RAROC is the most common acronym for the the most commonly used measure, the one that we discuss in this paper, this same measure is frequently referred to by other names and acronyms, and the term RAROC is also applied to other related performance measures.

${ }^{3}$ Smithson (2002), page 266, reports that $78 \%$ of the respondents to his 2002 Rutter Associates survey of credit portfolio managers, used RAROC to evaluate the performance of their portfolio of credit assets. PWC-EIU (2005), covering more than 200 medium sized and large banks and insurance companies worldwide, finds that more than half now conduct such capital allocation and most use the resulting return measures for various purposes, including business decision making, product pricing, and the determination of bonuses. They write that "economic capital is fast gaining critical mass within the industry". A more recent 2006 update of this survey shows even greater adoption. Asset managers also make widespread use of RAROC as a performance measure when acting on behalf of both retail and institutional investors.
} 
depend only on the conditional expected dollar returns of the financial asset given each possible outcome for aggregate economy wide output or market return. ${ }^{4}$ This 'pricing kernel', the negative relationship between expected dollar asset returns and aggregate output or market return, can then be used to obtain present values for any financial asset. The use of a single institution wide RAROC hurdle rate for financial valuation and performance measurement ignores the insights of this fifty years of work, asserting instead that financial values can be calculated from (one) extreme of a portfolio return distribution alone and without reference to aggregate economy wide payoffs.

The standard theory is far from perfect. It has not proved especially helpful to understanding asset price volatilities. Moreover financial markets are incomplete and investors subject to trading constraints, so there will be some uninsured exposure to different states with the same aggregate payoffs and some difference between investors in their valuation of these payoffs. But using RAROC with a single institution hurdle rate does not help correct financial valuation for either of these problems.

The contribution of this paper is to show that the valuation distortions from using RAROC with a single hurdle rate for all types of exposure can be quantitatively very large. Consider for example a comparison between a debt and an equity portfolio. In this case there are substantial differences in RAROC hurdles between equity and debt exposures, and between debt of different ratings. This is because of the different skewness of their respective return distributions. Returns on equities are right skewed, implying that the volatility of returns is large relative to the risk capital. Defaultable debt, in contrast, is left skewed and has a low volatility of returns relative to risk capital. As a result the RAROC hurdle appropriate for a debt portfolio is much lower than that for an equity portfolio, with the least risky investment grade debt having the lowest RAROC hurdles of all.

One reason why practitioners have employed a single institution RAROC hurdle rate so widely, without being aware of its inconsistency with basic financial economics, is that RAROC hurdle rate does just happen to be the same for different exposures when all asset returns are determined by a joint multi-variate normal distribution. This is the implausible but tractable version of standard financial theory routinely taught in most MBA finance classes. Under standard assumptions about investor behaviour the market cost of risk can be measured from VaR calculations for some (arbitrary) default threshold i.e. it turns out that in this class-room world a single hurdle rate RAROC works as a valuation measure.

\footnotetext{
${ }^{4}$ This is because risk averse investors can fully insure each with other for outcomes across states with the same level of aggregate output or market return
} 
This paper considers the real world situation when returns are not jointly normally distributed. If RAROC is to be used as a valuation tool then it must be used with an exposure specific hurdle rate, which has been adjusted to correct for differences in skewness and higher moments of the return distribution. The rationale is both standard and fairly obvious. In the frictionless setting of standard asset pricing theory, investors need compensation only for systematic risk measured by the correlation of returns with the market pricing factor. Thus exposures with relative large left-hand tails should be subject to relatively lower RAROC hurdles.

Although our formal model is different, our conclusions are consistent with the earlier contribution of Froot and Stein (1998), since like them our analysis suggests that institutions should price separately for systematic and balance sheet risk. Capital market frictions create a rationale for imposing an additional cost on the use of a financial institution's balance sheet. This implies that when using RAROC as a performance measure this means that the RAROC hurdle rate should be set on an exposure specific basis, with the hurdle the sum of an exposure specific correction for systematic risk and an institution wide measure of balance sheet risk.

The paper is arranged as follows. Section 2 provides some further motivation and discusses some related contributions to the literature. Section 3 is a review of the relationship between valation theory and the RAROC value metricc, drawing on the previous contributions of Crouhy et. al. (1999) and Milne and Onorato (1999), It applies the 'pricing kernel', the value metric of standard asset pricing theory, to investigate the determinants of zero net present value RAROC hurdle rates. Section 3.1 sets out our notation and assumptions. Section 3.2 briefly summarises the relevant asset pricing theory. Section 3.3 discusses the conditions under which different exposures can be compared using a single zero-NPV RAROC hurdle rate how these hurdle rates are affected by skewness of exposures. Section 4 is the core of the paper, presenting calculations of zero-NPV RAROC hurdle rates showing these differ substantially between different exposures. Section 5 is a short conclusion. 


\section{Motivation and literature review}

The use of capital modeling for the twin applications of default protection and for business management is widely discussed. ${ }^{5}$ It remains somewhat surprising that financial institutions have developed their own distinct capital based performance measures, rather than using the new present value tools used for example in project appraisal by non-financial corporates. The most obvious reason is the importance of credit standing to financial institutions. ${ }^{6}$ A further reason for the use of capital based performance measures - not much emphasised in the research literature - may be that capital allocation can be relatively easily extended to the important non-funded off-balance sheet exposures of financial institutions, where for example the familiar method of internal rate of return cannot.

If credit standing matters then a financial institution should make valuations relative to its own portfolio as well as to the market as a whole. There are two key academic articles exploring this point. Froot, Scharfstein and Stein (1993) point out that, faced with an increasing cost of raising external funds financial institutions will behave in a risk-averse fashion towards risks that are diversifiable at a market level. Specifically, a business unit's contribution to aggregate earnings volatility will be an important factor in the capital allocation and capital structure decisions and also in the decision to hedge earnings risk. Capital structure, hedging and capital budgeting are therefore inextricably linked together. ${ }^{7}$ Froot and Stein (1998) demonstrate that in a two period model that the hurdle rate for investments can be calculated from a two factor pricing model, namely the covariance of the return with the market $R_{m}$ and with the risks of the existing portfolio $R_{P}$ so $\mu_{i}=\gamma \operatorname{cov}\left(\mu_{i}, R_{m}\right)+\lambda \operatorname{cov}\left(\mu_{i}, R_{P}\right)$ where $\gamma$ is the market unit price of risk for the (market) priced factor $R_{m}$ and $\lambda$ is the unit cost for volatility of the portfolio i.e. they have a key practical message (which our analysis endorses) that both balance sheet and systematic risk must be separately priced. While not explicitly stated, their work reveals one obvious weakness of RAROC, that any attempt to incorporate both balance sheet and systematic risk within a single measure such as RAROC must fails even when returns are jointly multivariate normal since only rarely will $R_{P}$ be proportional to $R_{m}$. Our analysis complements that of Froot and Stein (1998) since we show, like them, that it is necessary to price separately for both systematic and balance sheet risk.

\footnotetext{
${ }^{5}$ See for example Zaik et. al. (1996) who note that models of risk capital are used for both for finding the proportion of equity to assets that minimizes the cost of funding and for risk-return assessment.

${ }^{6}$ Merton and Perold (1993) emphasize this point, arguing that performance measurement in financial institutions is different from industrial companies because their customers are their largest liability holders and as a consequence, a high credit rating is generally essential to maintain their business activities, e.g. as dealers or customers in OTC markets, to underwrite securities or to compete effectively in the corporate banking and deposit markets.

${ }^{7}$ For related discussion see also Stulz (1998)
} 
Another related branch of literature is that on coherent measures of risk, initiated by Artzner et. al. (1999). They demonstrate that the RAROC denominator VaR fails to satisfy their axiom of sub-additivity. This implies that it is possible, when combining portfolios, that the overall $\mathrm{VaR}$ of the combined portfolio can be greater than the sum of the individual VaRs. This potential absence of diversification benefits has been interpreted to mean that $\mathrm{VaR}$ is an unsatisfactory risk measure and that alternative measures which do not violate the axiom of sub-additivity, e.g. expected tail shortfall, should be preferred instead. Our analysis leads to an interpretation of the Artzner et. al. (1999) results that departs from that of the large literature on 'coherent' measures of risk. VaR remains an acceptable risk measure for assessing the probability of default (in this application there is no compelling reason to impose the axiom of sub-additivity) but a poor measure of risk for assessing risk-return trade-offs (when the axiom of sub-additivity has a strong appeal). Moreover our analysis indicate that even coherent performance measures can be inconstent with net present value. For example expected shortfall, while coherent, is still based only on part of the distribution and ignores the relationship with market returns.

The paper closest to our own is Crouhy et. al. (1999). They note that that RAROC does not measure NPV, when NPV is measured according the CAPM and there is a single RAROC hurdle rate. However they restrict their analysis to the comparison of arithmetic and log-normally distributed returns and do so without reference to underlying asset pricing theory. We provide a theoretical foundation and extend the quantitative comparisons to defaultable debt, revealing much larger differences in RAROC hurdles than they report.

\section{RAROC and financial valuation}

This section discusses the relationship between RAROC and the standard theory of financial valuation. ${ }^{8}$

\subsection{Notation and assumptions}

A financial institution considers an investment in an exposure indexed by $i$ held for a single period with an initial funding cost of $L_{i}(0) .{ }^{9}$ The exposure can be one of many different kinds, including a loan, a trading position, an off balance sheet commitment, or an insurance contract. $L_{i}(0)$ can be positive or negative. At the end of the period this exposure realises a payoff of $R_{i}(1)+A_{i}(1)$ with an expected value of $R_{i}(1)$ i.e. $A_{i}(1)$ measures the distribution of end-period payoffs about their mean value with $E\left[A_{i}(1)\right]=0$

\footnotetext{
${ }^{8}$ A fuller analysis of the relationship between RAROC and standard asset pricing theory appears in Milne and Onorato (2009).

${ }^{9}$ Throughout this section we distinguish the timing of cash flows and payoffs, using (0) to indicate the beginning of the period and

(1) the end of the period.
} 
In order to discuss balance sheet diversification we must also pay attention to the distribution of returns on the remainder of the institution's portfolio. Payoffs on the remainder of the portfolio are denoted by $\bar{R}_{i}(1)+\bar{A}_{i}(1)$, and on the total portfolio including $A_{i}$ by $R(1)+A(1)=\overline{R_{i}}(1)+R_{i}(1)+\bar{A}_{i}(1)+A_{i}(1)$. The upper case for the expected payoffs $R_{i}(0), \overline{R_{i}}(0)$, and $R(0)$ indicates that these are all absolute nominal monetary payoffs, not rates of return which we will distinguish using lower case e.g. $r$.

The distribution of total portfolio payoffs are described by the cumulative density function (CDF) denoted by a double $H H$ to indicate this is a multivariate distribution $H H\left(X_{i}, \overline{X_{i}}\right)=p\left(A_{i}(1) \leq X_{i}, \overline{A_{i}}(1) \leq \overline{X_{i}}\right)$. From $H H$ we can derive various single variable distribution which are of interest for risk measurement purposes:

1. the total portfolio CDF denoted as $H(X)=p\left(A(1)=A_{i}(1)+\overline{A_{i}}(1) \leq X\right)$,

2. the stand alone CDF denoted as $H_{i}\left(X_{i}\right)=p\left(A_{i}(1) \leq X_{i}\right)$,

3. and the total portfolio CDF without the investment $i$ denoted as $\bar{H}_{i}\left(\bar{X}_{i}\right)=p\left(\bar{A}_{i}(1) \leq \bar{X}_{i}\right)$.

All these distributions have zero expectations, since they describe payoffs relative to their expected values. Otherwise we place no restrictions on these distributions

Risk capital is measured using the quantiles of the CDF at a chosen probability threshold $p^{*}$. Thus the total portfolio risk capital is given by $-H H^{-1}\left(p^{*}\right)$ while the stand alone risk capital for investment $i$ is given by $-H_{i}^{-1}\left(p^{*}\right)$. Typically, since $p^{*}$ is small, $H^{-1}\left(p^{*}\right)$ is negative and much greater in absolute magnitude than expected net return, so risk capital is positive. We can also allow for diversification at portfolio level by measuring risk capital as $\bar{H}_{i}^{-1}\left(p^{*}\right)-H^{-1}\left(p^{*}\right)^{10}$. .We define return on risk capital or RAROC for exposure $i$ either as a standalone measure, $r_{i}^{r c}$ :

$$
r_{i}^{r c}=\frac{R_{i}(1)-r_{f} L_{i}(0)}{-H_{i}^{-1}\left(p^{*}\right)}
$$

or as a portfolio measure:

$$
r_{i}^{p r c}=\frac{R_{i}(1)-r_{f} L_{i}(0)}{\bar{H}_{i}^{-1}\left(p^{*}\right)-H^{-1}\left(p^{*}\right)}
$$

\footnotetext{
${ }^{10}$ Note that under this definition risk capital a VaR type quantile risk measure associated with period 1 return distribution and therefore differs from equity capital which is a period 0 source of funding.
} 
In the remainder of the paper we will consider only the stand alone measure. This is not because the portfolio measure is unimportant for risk management decisions, but because as discussed in the following sub-section financial valuation depends only on the market pricing kernel. Thus, a point often forgotten by practitioners, in order to measure value created for investors the benefits of diversification should be assessed at the level of the aggregate economy and depend on the contribution to aggregate investor portfolio risk exposure not to firm portfolio risk exposure.

\subsection{Asset pricing theory and market valuation}

We denote the time $t=0$ market value of exposure $i$ by $\hat{A}_{i}(0) .{ }^{11}$ In this subsection we outline the standard asset pricing theory that we use to model this market value $\hat{A}_{i}(0) .{ }^{12}$ Under the assumption that all risks are tradeable in liquid markets the market value of exposure $i$ can be expressed as: $:^{13}$

$$
\hat{A}_{i}(0)=E\left[z\left(R_{i}(1)+A_{i}(1)\right)\right]=E[z] R_{i}(1)+E\left[z A_{i}(1)\right]
$$

where $z$ is a pricing (or stochastic discount) factor. The market rate of return on asset $i$ is defined as:

$$
r_{i}=\frac{R_{i}(1)}{\hat{A}_{i}(0)}
$$

We will further assume that markets are complete. ${ }^{14} z$ is then unique and represents the marginal valuations by investors of all possible asset returns. ${ }^{15}$ The content of this theory comes from the fact that $z$ is the same for all assets. This theory supports a number of widely standard results about asset pricing. Investors do not

\footnotetext{
${ }^{11}$ We use a 'hat' to distinguish market measures (e.g. $\hat{A}_{i}$ )from the corresponding accounting measure (the accounting valuation of the exposure measured at cost would be $A_{i}=L_{i}$. We use the same 'hat' for the zero-NPV RAROC, since this is the return on capital achieved by an exposure with a market value $\hat{A}_{i}(0)$ that equals its accounting value measured on a cost of acquisition basis $L_{i}(0)$.

${ }^{12}$ This theory is described in many textbooks. Our presentation follows that in part I of Cochrane (2005).

${ }^{13}$ This is Cochrane (2005), equation 1.4, with our slightly amended notation.

${ }^{14}$ Our main results still obtain under the weaker assumption that all assets are traded in liquid markets (absence of arbitrage opportunities). Suppose first that we are considering the RAROC $\backslash$ hurdle for an asset that is 'spanned' by all existing traded assets. In this case, while there is no unique stochastic discount factor $z$, market prices are still uniquely determined and our propositions continue to hold. If the financial asset is not so spanned then no unique RAROC hurdle exists and so RAROC $\backslash$ certainly cannot be used for performance measurement (in this case there is instead a minimum hurdle (below which an exposure is definitely

${ }^{15}$ The ratio of $z^{a}$ and $z^{b}$ for two different outcomes $A_{i}^{a}$ and $A_{i}^{b}$ represents the willingness of investors to

exchange a small increase in return in the event of outcome $A_{i}^{a}$ for a small decrease in return in the event of

outcome $A_{i}^{b}$.
} 
need to be compensated for risks that can be diversified through trading of risky investment instruments. Compensation is required only for risks that are correlated with the investor valuation of returns (those that co-vary with $z$ ). Portfolio or exposure specific characteristics will not affect valuations.

This theory can be represented in many equivalent ways. We will use the following "security line representation" because we will make use of it when providing an illustrative example in a later section on how to measure the risk adjusted value creation of two distinctive exposures. By using the security line representation it is possible to express the correlation of returns between $\frac{A_{i}(1)}{\hat{A}_{i}(0)}$ and $z$ in terms of $\rho_{i z}$, and the standard deviation of $\frac{A_{i}(1)}{\hat{A}_{i}(0)}$ in terms of $\sigma_{i}$ :

$$
r_{i}=r_{f}-\rho_{i z} \sigma_{i} \sigma_{z}
$$

This shows that excess returns $\left(r_{i}-r_{f}\right)$ are linear function of both correlation of returns with $z$ and of the standard deviation of returns. Since $\rho_{i z} \geq-1$ and $\frac{r_{i}-r_{f}}{\sigma_{i}} \leq \sigma_{z}$, this in turn indicates that $\sigma_{z}$ is the maximum achievable excess market return for accepting a unit, i.e. one standard deviation, of risk. The $z$ are not directly observed. They are a set of relative valuations inferred from the prices of investment assets. However given further assumptions about either investor preferences, or the determinants and distribution of investor returns, $z$ can be modelled using observable economic or market factors, yielding all standard asset

\subsection{Defining the right hurdle rate: the zero NPV RAROC}

This sub-section defines the appropriate hurdle rate to be compared to the previously described RAROC $r_{i}^{r c}$ (return on risk capital) performance measure to measure value creation

$$
r_{i}^{r c}=\frac{R_{i}(1)-r_{f} L_{i}(0)}{-H_{i}^{-1}\left(p^{*}\right)}
$$

Let us define the zero-NPV hurdle rate for RAROC. Net present value or NPV is the difference between the market value of an exposure $\hat{A}_{i}(0)$ and its cost of acquisition $L_{i}(0)$ and can therefore be written as: ${ }^{16}$

\footnotetext{
${ }^{16}$ This is the NPV formula in a single-period setting. Multi-period NPV formulations are obtained from the valuation of an asset traded at period 0 offering period $t$ future expected payoffs $R_{i}(t)+A_{i}(t)$ where $R_{i}(t)$ is the known expected return and $A_{i}(t)$ is the distribution around that return for $t=1,2, \ldots \ldots, T$.
} 


$$
N P V=\hat{A}_{i}(0)-L_{i}(0)
$$

This is a net present value because it is the present discounted value of future returns less the current cost of acquisition of the exposure. Exposures are value creating and should be acquired if and only if $N P V \succ 0$. The stand alone return on risk capital on a zero-NPV exposure (one where $\hat{A}_{i}(0)=L_{i}(0)$ ) can then be written as the following ratio

$$
\hat{r}_{i}^{r c}=\frac{R_{i}(1)-r_{f} \hat{A}_{i}(0)}{-H^{-1}\left(p^{*}\right)}
$$

An alternative and equivalent decision criteria to NPV $>0$ is then to accept all exposures for which $r_{i}^{r c}>\hat{r}_{i}^{r c}$ i.e. $\hat{r}_{i}^{r c}$ is the required rate of return on risk capital or RAROC hurdle rate.

We now examine the determinants of the the zero-NPV RAROC hurdle rates, showing that an increase in skewness increases risk capital relative to required returns and so reduces hurdle rate. By substituting equation (4) and (5) into (8) we can rewrite this zero-NPV hurdle rate as:

$$
\hat{r}_{i}^{r c}=\frac{\hat{A}_{i}(0) \rho_{i, z} \sigma_{i} \sigma_{z}}{-H_{i}^{-1}\left(p^{*}\right)}
$$

This shows that it is legitimate to use RAROC with single institution wide hurdle rate for all exposures $i=1,2, \ldots \ldots ., I$ only if the required return premium for each exposure (the numerator of equation (9) is proportional to the risk capital (the denominator of this equation). The conditions for this to be true are extremely demanding. In particular differences in skewness will affect the zero-NPV hurdle rate.

A sufficient condition for the return on standalone risk capital to be the same for all exposures is that the distribution of asset returns $A^{i}(1)$ all have the same correlation with the stochastic discount factor and that for any given $i$ the distribution of $i$ can be expressed as a mean-preserving spread of a single underlying asset return distribution $A^{+}(1)$ i.e. that the skewness and higher moments of all distributions are the same. ${ }^{17}$ In this case $\rho_{i}=\rho$ is the same for all assets and $H\left(A^{i}(1)\right)$ is proportional to $\sigma_{i}$. An example where this is the case is when all asset returns obey a multivariate normal distribution. This is not a necessary condition because it is just possible that differences is $\rho_{i}$ between assets are exactly offset by differences in the ratio of $H\left(A^{i}(1)\right)$ to $\sigma_{i}$; but this is a very implausible situation. It is thus clear that ZeroNPV RAROC hurdles can vary considerably, depending upon the shape of the return distribution.

\footnotetext{
${ }^{17}$ For a formal proof of this statement see Milne and Onorato (2008)
} 


\section{Calculations of zero-NPV RAROC hurdles}

This section presents some illustrative calculations of the RAROC hurdle rate, the return on risk capital that must be achieved by an NPV positive portfolios invested either in equities or in debt securities of varying credit qualities. It turns out that the variability in these hurdle rates, from one exposure to another, is not just an academic or theoretical concern, there are very large differences in these hurdle rates of a sufficient magnitude to be of considerable practical concern. These calculations suggest that using a single institution wide RAROC measure leads to substantial misvaluation of investment opportunities.

How are these calculations conducted? We begin making some specific but plausible assumptions about the distribution of returns on different assets (equity and various qualities of debt) at the end of a fixed holding period. ${ }^{18}$ These assumptions determine both the distribution of asset returns and, most importantly, the relationship between these returns and aggregate market return.

We then do two things. First we apply the standard asset pricing tools described in the previous section to value each assets (their 'present value') and hence obtain an expected market return on each asset during the holding period. Second we compute the amount of risk capital that has to be held against each asset in order to maintain the probability of default to a given threshold i.e. we calculate its value at risk (risk capital). The RAROC hurdle rate on each asset is then the expected market return less the cost of financing the purchase of the asset, expressed as a ratio of risk capital.

As the previous section has explained, the actual prospective RAROC on any asset can be higher or lower than this RAROC hurdle; RAROC will exceed the hurdle if the cost of acquiring the asset is less than the present market value (i.e. net present value is positive) and it will be below the hurdle if this cost is less than the present market value (so that net present value is negative). We first calculate the RAROC hurdle for different assets (see table 1). This hurdle rate varies a great deal from one category of asset to another. We then examine the actual prospective RAROC for both positive NPV exposures (see Table 2) and negative NPV exposures (see Table 3)

Our calculations make the following specific assumptions:

\footnotetext{
${ }^{18}$ It would be possible to extend to the case of multiple periods of investment and consumption, rather than a single holding period, but this is not relevant to our argument.
} 
- The investment horizon and also maturity of debt securities are one year (having these time periods the same means that there is no interest rate risk.)

- All investors have quadratic preferences, so the required returns on both equity and debt can be calculated using the capital asset pricing model. Specifically the required (zero NPV) return on portfolio $i$ can be calculated from $r_{i}=r_{f}+\rho_{i m} \sigma_{i} \lambda$ the equation under the CAPM assumptions) (this corresponds to equation (4) where $\rho_{i m}$ is the correlation between portfolio returns and market returns, $r_{f}$ is the risk free interest rate and $\lambda$ is the slope of the security market line (the 'Sharpe ratio') $\lambda=\left(r_{m}-r_{f}\right) / \sigma_{m}$. For our illustrations we assume $r_{f}=5 \%$ and $r_{m}=11 \%$ and $\sigma_{m}=10 \%$. The use of the CAPM is different from that in the usual MBA presentations, we are not here assuming that returns are normally distributed. ${ }^{19}$

- The end period value of the equity portfolio is log-normally distributed and is calculated as

$$
R_{i}(1)+A_{i}(1)=\exp (\mu+\sigma M)
$$

Where $\mu$ and $\sigma$ are the log rates of return (instantaneous growth) and log-standard deviation of return. $\mu$ and $\sigma$ are chosen so that the expected return $r=\int \exp (\mu+\sigma M) \phi(m) d M=10 \%$ and the standard deviation of this return $s=\sqrt{\int[\exp (\mu+\sigma M)-r]^{2} \phi(m) d M}=11 \%$ i.e. the expected return and standard deviation of the equity match that available from the market portfolio. $\mathrm{M}$ is the underlying standard normally distributed aggregate market risk factor.

- The returns on portfolios of risky (defaultable) debt are determined by the simple single aggregate factor asymptotic Vasicek model.

$$
R_{i}(1)+A_{i}(1)=1-L G D^{*} N\left(\frac{N^{-1}(P D)+\omega^{0.5} M}{\sqrt{1-\omega}}\right)
$$

Where:

LGD is the loss given default that we have assumed equal to 0.4;

PD is the default probability and these are reported in the third column of Table 1 for the various debt classes;

$\omega=0.4$ is the asset correlation;

$\mathrm{M}$ is the same underlying standard normally distributed aggregate market risk factor that determines the returns on the equity portfolio.

\footnotetext{
${ }^{19}$ The assumption of quadratic preferences is not a particularly great restriction. Extending valuation calculations to allow for nonquadratic preferences makes has only a second order impact on asset prices, a point illustrated, for example, by the asset pricing calcuations presented in Sharpe (2007).
} 
We compare the equity portfolio with six different qualities of defaultable debt, ranging from $\mathrm{A}^{-}$to $\mathrm{CCC}$. The annual default probabilities PD are taken from the Fitch Ratings Global Corporate Finance Average Cumulative Default Rates 1990-2007. Table 1 presents the resulting calculations of the zero-NPV RAROC hurdle rates.

The standard deviation, and correlation and required return on the equity portfolio (columns (4), (5) and (6)) are determined by our assumption that equity portfolio returns correspond exactly to the those for the market portfolio as a whole (we are in effect assuming that corporate debt represents a fairly small proportion of the entire market portfolio). The corresponding standard deviation and correlation with the market for the debt portfolios are calculated from equation (11) using numerical integration and column (6) from the CAPM. The risk capital in column (7) is $-H_{i}^{-1}\left(p^{*}\right)$ calculated using the default probability threshold $p^{*}=99.97 \%$ calculated using (10) and (11). This threshold is a common industry choice for credit and value at risk calculations at a one year horizon. Finally the RAROC hurdle is the required risk premium (the required return less the risk free rate) as a percentage of risk capital.

Table 1: calculations of the RAROC hurdle for different asset exposures

\begin{tabular}{|c|c|c|c|c|c|c|c|}
\hline $\begin{array}{c}\text { Exposure } \\
\text { (1) }\end{array}$ & $\begin{array}{c}\text { Rating } \\
\text { (2) }\end{array}$ & $\begin{array}{c}\text { Default } \\
\text { probability } \\
\% \\
(3)\end{array}$ & $\begin{array}{c}\text { standard } \\
\text { deviation } \\
\% \\
(4)\end{array}$ & $\begin{array}{l}\text { Correlation } \\
\text { with } \\
\text { market } \\
\text { (5) }\end{array}$ & $\begin{array}{l}\text { required } \\
\text { return } \\
\% \\
(6)\end{array}$ & $\begin{array}{c}\text { Risk } \\
\text { capital } \\
\% \\
(7)\end{array}$ & $\begin{array}{c}\text { RAROC } \\
\text { hurdle \% } \\
(8)= \\
\left((6)-r_{f}\right) /(7)\end{array}$ \\
\hline Equity & & & 10.00 & 1.00 & 11.00 & 29.35 & 20.44 \\
\hline Debt & $A^{-}$ & 0.10 & 0.22 & 0.40 & 5.05 & 4.90 & 1.10 \\
\hline Debt & BBB & 0.26 & 0.45 & 0.48 & 5.13 & 8.74 & 1.47 \\
\hline Debt & $\mathrm{BB}^{+}$ & 0.69 & 0.90 & 0.57 & 5.31 & 14.62 & 2.11 \\
\hline Debt & BB & 1.24 & 1.37 & 0.63 & 5.52 & 19.07 & 2.71 \\
\hline Debt & $\mathrm{B}^{+}$ & 1.44 & 1.52 & 0.65 & 5.59 & 20.28 & 2.91 \\
\hline Debt & CCC & 21.91 & 9.63 & 0.94 & 10.43 & 36.07 & 15.05 \\
\hline
\end{tabular}

Notes: The risk free rate of interest is $r_{f}=5 \%$. In the case of the equity portfolio column (4), (5) and 6) are all determined by the assumption that equity returns match those on the market as a whole, i.e. we are assuming a market return of $r_{m}=11 \%$ and standard deviation of $\sigma_{m}=10 \%$. In the case of debt Column (3) is an assumed parameter and the standard deviation and market return shown in columns (4) and (5) are calculated from the assumed Vasicek return distribution, while column (6) is the required return calculated according to the CAPM from (4) and (5) using $r_{f}+\rho_{i, m} \sigma_{i} *\left(r_{m}-r_{f}\right) / \sigma_{m}$. For both equity and debt the risk capital in column (7) is calculated as the difference between the mean expected return and the $99.97 \%$ left hand tail of the assumed return distribution. Columns (3), (4), (6) and (7) are all percentages of the beginning of period market value of the exposure.

Before discussing the differences in RAROC hurdles it is worth discussing some other aspects of the calculations presented in this table. The standard deviation of returns on debt are much smaller, as a percentage of market value, than those on equity. Investment grade debt has especially low volatility of returns (recall this is short term one year debt so there is no interest rate risk over a one year holding 
horizon) but even the speculative grade $\left(\mathrm{B}^{+}\right.$and $\mathrm{BB}$ ) has much less volatility than equity. Only the debt in immediate risk of default (CCC) has a volatility of returns close to that of equity (not all these returns and volatilities are percentages of market value, such stressed debt would trade at only a small fraction of its par value so that volatility relative to par will be much smaller than shown here.)

Correlations with the market are also somewhat smaller than for equity, especially for the higher grade debt. This is a very plausible feature of the Vasicek model that underlies these calculations, since there is a very non-linear relationship between aggregate market returns and default. Small deviations in market returns about their expected level have only a minor impact on default rates, but a large decline in market returns is associated with a proportionately much bigger rise in default and credit losses. Therefore correlation is less than one to one, even when the same aggregate risk factor drives both market returns and corporate debt default.

The required returns (column (6) ) should all be compared to the risk free rate of $5 \%$. As a consequence of low standard deviation and relatively low correlation with the market, the required risk premium on $\mathrm{A}^{-}$debt is only 5 basis points (again recall this is only one year debt so a small risk premium is plausible). We must acknowledge that the observed market risk premium on such debt is in practice likely to be higher than such a theoretical calculation because of liquidity and other market frictions; none the less it is quite appropriate that it should be far less than the risk premium on equity. Even for $\mathrm{B}^{+}$debt the risk premium we calculate is only 59 basis points, again much lower than the $6 \%$ on equity. Only the distressed CCC debt, on the verge of default, has a risk premium similar to that of equity.

Relative to the market value of these exposures, the risk capital for debt is generally smaller than that for equity (column (7), the exception is the CCC debt), but still large in comparison to the risk premia on required returns. As a result the zero-NPV RAROC hurdle is very much lower for debt than for equity - our calculations suggest as a rough rule of thumb that the RAROC hurdle for debt should be only about one tenth of that for equity exposures, a very large difference indeed. Even for the distressed CCC debt, which is in many ways similar to equity, the zero-NPV RAROC hurdle is somewhat smaller than on equity, a consequence of the large amount of required risk capital relative to the market value of the exposure.

Tables 2 and 3 present some related calculations, in order to illustrate the relationship between the RAROC hurdle, the actual RAROC, and value creation. In table 2 we have assumed a cost of acquisition $L_{i}(0)$ of $98 \%$ of the market value $A_{i}(0)$ so that value is being created.

Table 2: actual versus hurdle RAROC when exposure creates value 


\begin{tabular}{|l|l|r|r|r|r|}
\hline $\begin{array}{c}\text { Exposure } \\
\text { (acquired for 98\% } \\
\text { of market value) }\end{array}$ & Rating & $\begin{array}{c}\text { Expected } \\
\text { return \% }\end{array}$ & $\begin{array}{c}\text { cost of } \\
\text { finance } \\
\%\end{array}$ & $\begin{array}{c}\text { actual } \\
\text { RAROC } \\
\%\end{array}$ & $\begin{array}{c}\text { RAROC } \\
\text { hurdle } \\
\%\end{array}$ \\
\hline Equity & & 11.22 & 4.90 & 21.12 & 20.44 \\
\hline Debt & $\mathrm{A}^{-}$ & 5.16 & 4.90 & 3.14 & 1.10 \\
\hline Debt & $\mathrm{BBB}^{+}$ & 5.23 & 4.90 & 2.61 & 1.47 \\
\hline Debt & $\mathrm{BB}^{+}$ & 5.42 & 4.90 & 2.79 & 2.11 \\
\hline Debt & $\mathrm{BB}^{+}$ & 5.63 & 4.90 & 3.24 & 2.71 \\
\hline Debt & $\mathrm{B}^{+}$ & 5.70 & 4.90 & 3.40 & 2.91 \\
\hline Debt & $\mathrm{CCC}$ & 10.64 & 4.90 & 15.32 & 15.05 \\
\hline
\end{tabular}

Note: calculation is the same as for Table 1, except that all percentages are percentage of the purchase value not the market value.

As we can see in this case all actual RAROC are greater than the hurdle and therefore we are creating value for the financial Institution. Table 3, is the opposite case of a value destroying investment where the cost of acquisition is $102 \%$ of the market value. Now we observe exactly the opposite and the actual RAROC is below the RAROC hurdle.

Table 3: actual versus hurdle RAROC when exposure destroys value

\begin{tabular}{|l|l|r|r|r|r|}
\hline $\begin{array}{c}\text { Exposure } \\
\text { (acquired for 102\% } \\
\text { of market value) }\end{array}$ & rating & $\begin{array}{c}\text { Expected } \\
\text { return \% }\end{array}$ & $\begin{array}{c}\text { actual } \\
\text { cost of } \\
\text { finance \% }\end{array}$ & $\begin{array}{c}\text { RAROC } \\
\text { \% }\end{array}$ & $\begin{array}{c}\text { RAROC } \\
\text { hurdle } \\
\text { \% }\end{array}$ \\
\hline Equity & & 10.78 & 5.10 & 19.76 & 20.44 \\
\hline Debt & $\mathrm{A}^{-}$ & 4.95 & 5.10 & -0.95 & 1.10 \\
\hline Debt & $\mathrm{BBB}^{+}$ & 5.03 & 5.10 & 0.33 & 1.47 \\
\hline Debt & $\mathrm{BB}^{+}$ & 5.20 & 5.10 & 1.43 & 2.11 \\
\hline Debt & $\mathrm{BB}$ & 5.41 & 5.10 & 2.19 & 2.71 \\
\hline Debt & $\mathrm{B}^{+}$ & 5.48 & 5.10 & 2.41 & 2.91 \\
\hline Debt & $\mathrm{CCC}$ & 10.22 & 5.10 & 14.77 & 15.05 \\
\hline
\end{tabular}

Note: calculation is the same as for Table 2

\section{Concluding remarks}

This paper has examined the relationship between risk capital (the contribution of an exposure to institution wide default risk) and required returns. We have examined the common industry measure return on risk capital i.e. RAROC and its use as a performance measure with a single institution wide hurdle rate. In all realistic situations the hurdle rate, the required return on risk capital, must be adjusted on an exposure specific basis. Such an adjustment is needed in order to correct for differences in skewness (the reason why the RAROC hurdles differ so much in Table 1). The rationale for these results is both standard and once understood fairly obvious. In the frictionless setting of standard asset pricing theory, investors need compensation only for systematic risk (correlation of returns with $z$ ). Thus exposures with relative large 
left-hand tails or relatively high correlation with the institution's own balance sheet should be subject to relatively low RAROC hurdles.

The usual current practice in the industry is to apply a single institution wide RAROC hurdle chosen with reference to a benchmark, typically calculated from the return on book equity of a market peer group. This can lead to substantial misallocation of capital. To illustrate the point consider the use of a typical institution wide hurdle rate of $15 \%$ when actual returns are those described in Table 2 . The $15 \%$ hurdle rate suggest value creation for the equity exposure of $21.12-$ $15.0=6.12 \%$ when the actual return on capital is only $21.12-20.44=0.68 \%$. In contrast the $15 \%$ hurdle rate suggest that the $\mathrm{A}^{-}$debt exposure has a negative return on capital of 3.14$15.0=-11.86 \%$ whereas in fact the actual return on capital is $3.14-1.10=+2.06 \%$. Thus with this constant hurdle rate shareholders are missing out entirely on value creating investment opportunities in good quality debt and, obtaining an unnecessarily low return on capital. As the equity example of Table 3 indicates, with a fixed hurdle rate of say $15 \%$, it is possible that the firm may invest shareholder funds in exposures even when these are in fact value destroying.

We note that, conducted RAROC value assessment correctly, with exposure specific hurdle rates based as here on the pricing-kernel removes much of the conflict between shareholders on the one hand and depositors or other debt holders on the other. Debt holders want the bank to be very safe, i.e. making a conservative choice of the threshold for the calculation of the risk capital in the RAROC denominator and hence running the institution with relatively low leverage. The key point is that this more conservative choice of threshold, while it increases the capital allocated to each exposure, also lowers the zero-NPV RAROC hurdle. The value creating exposures available to the bank are exactly the same, whether it is run aggressively with high leverage or conservatively with low leverage.

The conflict between shareholdes and debt holders is not entirely removed. Since shareholder capital is in limited supply a more conservative choice of leverage will force the bank to forgo some value creating but relatively low return on capital opportunities. But the use of single institution wide RAROC hurdle rates exaggerate the shareholder benefits of leverage and encouraged banks and other financial institutions to repay far too much capital to shareholders and 
acquire excessive debt, encouraging the excess leverage that has contributed to the current financial crisis. Thus our analysis should help financial regulators and supervisors ensure that financial institions are appropriately managing their risks from the perseictive of debt and deposit holders, and financial system stability, as well as the narrower perspective of shareholder value creation.

We conclude with a final suggestion. Recognising that illiquid balance sheet exposures are in reality more costly than traded assets because they exposure firms to risk of financial distress it is then necessary to conduct two risk adjustments to correctly value financial institution exposures, one adjustment for systematic risk and another for balance sheet risks. This can be done by calculating exposure specific RAROC hurdles, of the kind shown in our Table 1, and then adding an additional institutional wide increment to the RAROC hurdle to capture balance sheet risks. This further institution wide increment will be the same for all exposures and reflect the cost of risk capital over and above the cost of systematic risk. Alternatively, and equivalently, it is possible to adjust the numerator of the RAROC equation for systematic risk (effectively deducting not just the cost of funds but also the systematic cost of risk according to some version of our equation (5)). In either case we are then, as recommended by Froot and Stein (1998), pricing separately for systematic and balance sheet risks. We believe that all practitioners need to take heed of this advice.

\section{References}

1) Artzner, P.; F Delbaen, J-M Eber, and D Heath, (1999) Coherent Measures of Risk, Mathematical Finance, 9: 203-228.

2) Cochrane, John H (2005) Asset Pricing: Revised, Princeton University Press

3) Crouhy; M, S Turnbull and Wakeman (1999) Measuring Risk-adjusted performance, Journal of Risk, Vol 2 no 1, Fall, pp. 5-35.

4) Dev, Ashish (2006) Economic Capital: A Practitioner's Guide, Risk Books

5) Ernst and Young (2007) Economic Capital Management: the Investor's Perspective

6) Froot, K., Scharfstein, D; and Stein J (1993) Risk Management: Coordinating Corporate Investment and Financing Policies, Journal of Finance, vol. 48(5), pages 1629-58

7) Froot, K. and Stein, J. (1998) Risk Management, Capital Budgeting and Capital Structure Policy for financial institutions: An Integrated Approach, Journal of Financial Economics, 47: 55-82.

8) KPMG (2004) Basel II- A closer look: Managing Economic Capital. downloadable from several national KPMG websites including www.us.kpmg.com

9) Matten, Chris (2001) Managing Bank Capital, 2nd edition, Wiley

10) Merton, R (1973), `An Intertemporal Capital Asset Pricing Model', Econometrica, 41, pages 867-887.

11) Merton, R. and Perold, A. (1993) Theory of risk capital in financial firms, Journal of Applied Corporate Finance, 6: 16-32.

12) PWC-Economic Intelligence Unit (2005) Effective capital management: Economic Capital as an Industry Standard? which can be found via http://searchpwc.com/extweb/pubsrch.nsf/PubSrchForm

13) Zaik E., Walter J., Kelling G. and James C. (1996) RAROC at Bank of America: from theory to practice, Journal of Applied Corporate Finance. 